\title{
The Importance of the Jejunal Vascular Anatomical Variability of the Laboratory Rat in the Experimental Surgery
}

\author{
Jan Danko $^{1 *}$, Katarina Vdoviakova ${ }^{1}$, Lenka Kresakova ${ }^{1}$, Peter Massanyi ${ }^{2}$, Norbert Lukac ${ }^{2}$ and Robert \\ Stawarz ${ }^{3}$ \\ 1. University of Veterinary Medicine and Pharmacy in Kosice, Kosice, Slovak Republic \\ 2. Slovak University of Agriculture in Nitra, Nitra, Slovak Republic \\ 3. Pedagogical University of Krakow, Krakow, Poland \\ * Corresponding author: jan.danko@uvlf.sk
}

The sicknesses of the gastrointestinal organs and their therapy form a big part in the surgical research of the medical investigation [1,2]. Many structures or organs in the laboratory animals were studied in several research $[3,4]$, but some details have not yet been examined. The objective of this study was investigated the morphometric parameters, the anatomical arrangement and number of jejunal arteries and their relationship to the intestinal length in rats. The experiment was carried out on 50 one-year-old laboratory rats, breed Wistar of both sexes and weighing approximately 350-520 g. We measured the length of the jejunum after midlaparotomy and then we prepared corrosion casts of the arteries of the jejunum. We observed that the jejunal arteries originated from the cranial mesenteric artery, which is the thickest branch of the abdominal aorta. In $26 \%$ of the cases we observed 14 jejunal trunks, and 4 jejunal arteries which originated separately from the cranial mesenteric artery. In $26 \%$ of the cases we detected 16 jejunal trunks, and 3 jejunal arteries which originated separately from the cranial mesenteric artery. In $24 \%$ of the cases we found 18, and in another $24 \%$ cases, 20 jejunal trunks. The latest edition of the Veterinary Anatomic Nomenclature was consulted throughout this study [5]. The results of our study showed that the number of jejunal trunks and jejunal arteries increased continually with the elongation of the rat intestine and body weight. Our results point to the importance of research of the circulatory system of the rat intestine for future experimental transplantation of digestive organs.

\section{References:}

[1] Y Ma and ZY Guo, Hepatobiliary Pancreatic Diseases 7 (2008), p. 156

[2] E Majorova et al., Pediatrie pro praxi 4 (2004), p. 209.

[3] HL Foster et al. in "The mouse in biomedical research III", ed. JG Fox et al. (Academic Press, NY) p. 257.

[4] M Abidu-Figueiredo et al., Pesquisa Veterinária Brasileira 5 (2008), p. 237.

[5] J Danko et al. "Nomina Anatomica Veterinaria", ed. J Danko et al. (University of Veterinary Medicine and Pharmacy, Kosice) p. 67.

[6] This work was supported by project VEGA 1/0050/19. 